\title{
In-Situ Infrared Spectroscopy of Buried Organic Monolayers: Influence of the Substrate on Titanium Reactivity with a Langmuir Blodgett Film
}

\author{
Carrie L. Donley ${ }^{\dagger \S}$, Jason J. Blackstock ${ }^{\dagger}$, William F. Stickle ${ }^{\ddagger}$, \\ Duncan R. Stewart ${ }^{\dagger *}, R$. Stanley Williams ${ }^{\dagger}$ \\ ${ }^{\dagger}$ Quantum Science Research, Hewlett-Packard Labs, 1501 Page Mill Road, Palo Alto, CA \\ ${ }^{\ddagger}$ Analytical and Development Laboratories, Hewlett-Packard Company, Corvallis, Oregon \\ $\S$ Current Address: University of North Carolina, Institute for Advanced Materials, 243 Chapman Hall, Chapel \\ Hill, NC 27599 \\ *Author to whom correspondence should be addressed: duncan.stewart@hp.com
}

\section{Supplementary Information}

Included below in Figure S1 are x-ray photoelectron spectra (XPS) illustrating chemical analysis of the deposited Ti overlayer for each $\mathrm{Au}, \mathrm{SiO}_{2}$ and $\mathrm{PtO}_{\mathrm{x}}$ substrate studied by attenuated total reflection infrared spectroscopy (ATR-IR) in the main body of this work. This material is available free of charge via the Internet at http://pubs.acs.org. 
a
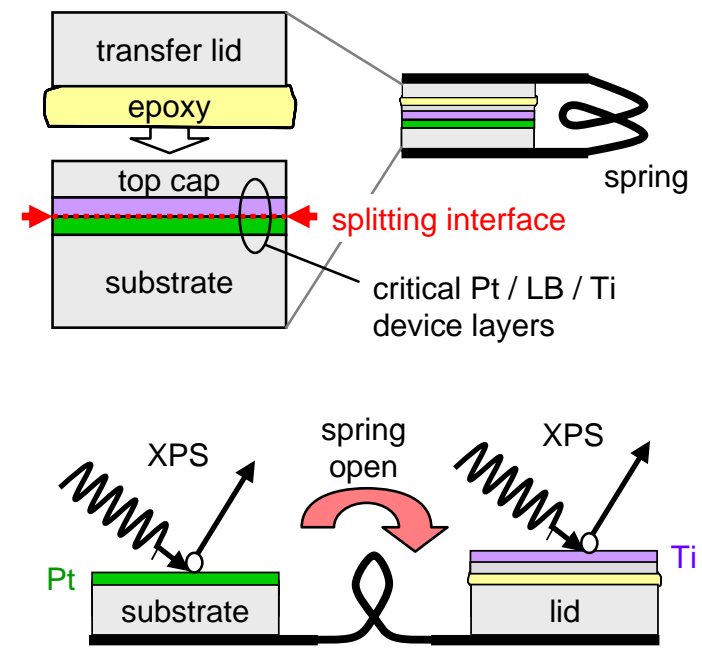

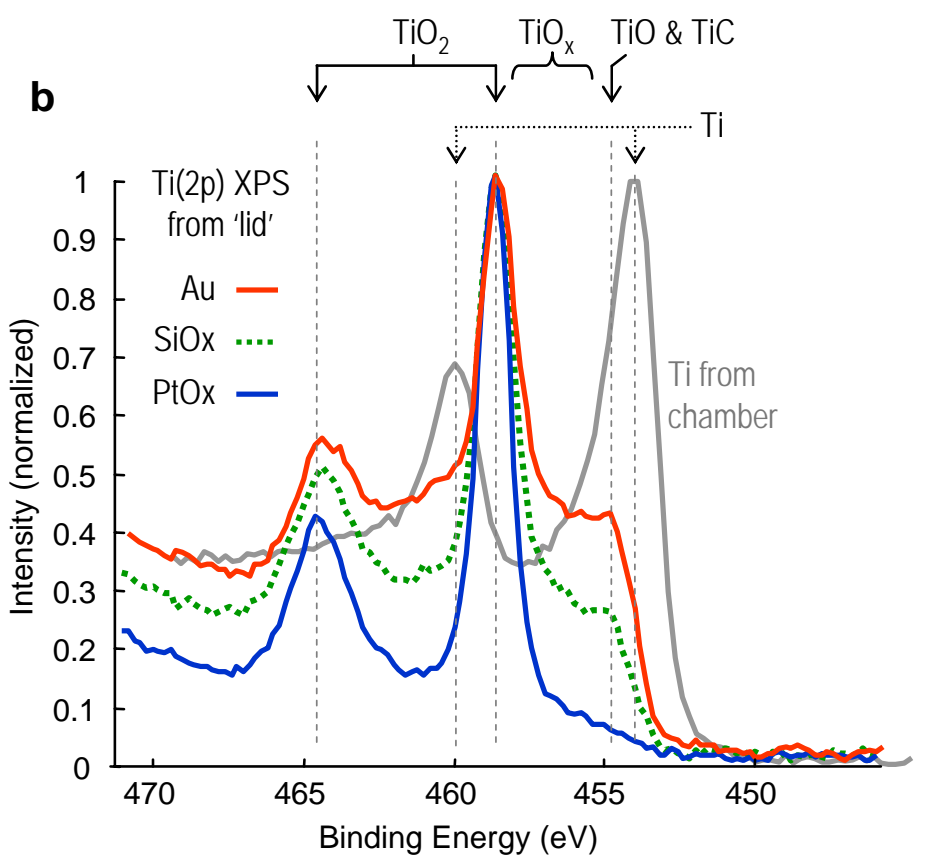

Figure S1: (a) X-ray photoelectron spectroscopy (XPS) of the buried interfaces near the critical Langmuir Blodgett (LB) organic monolayer was conducted on specially delaminated samples. New samples nominally equivalent to the ATR-IR samples were fabricated with an additional top cap layer of Au. For example, in the PtOx substrate case, the XPS sample structure was $\mathrm{Si} / \mathrm{SiO}_{2} / \mathrm{Pt}(5 \mathrm{~nm}) / \mathrm{PtO}_{\mathrm{x}}(2.5 \mathrm{~nm}) / \mathrm{LB} / \mathrm{Ti}(5 \mathrm{~nm}) / \mathrm{Au}$ top cap (100 nm). A transfer lid of glass or silicon was then affixed by epoxy, connected to a spring hinge, loaded into high vacuum (< $10^{-7}$ Torr), then delaminated (sprung open), and XPS analysis conducted on both the exposed substrate surface and the exposed upper 'lid' surface. Details of this procedure have been previously published. ${ }^{1}$ The specimens were analyzed using a PHI Quantera Scanning ESCA equipped with a monochromatic aluminum x-ray source with a photon energy of $1486.6 \mathrm{eV}$. The data were acquired using a $200 \mu \mathrm{m}$ diameter photon beam with the electron detector at an angle of $45^{\circ}$ to the surface normal. The high-resolution spectral data were acquired at a pass energy of $55 \mathrm{eV}$ at $0.1 \mathrm{eV} / \mathrm{step}$, and all data was charge corrected to C (1s) at 284.8eV. (b) Ti(2p) XPS data for the upper 'lid' surface of the three structures examined by ATR-IR in the main paper, namely the LB / Ti layers deposited onto $\mathrm{Au}, \mathrm{SiO}_{2}$ and $\mathrm{PtO}_{\mathrm{x}}$ substrates. Peak assignments are shown above the spectra $(\mathrm{Ti}=454.0 \mathrm{eV}, \mathrm{TiO} / \mathrm{TiC}=$ $\left.454.7 \mathrm{eV}, \mathrm{TiO}_{2}=458.6 \mathrm{eV}\right)^{2}$. Also shown for reference (grey line) is a spectrum of mostly-metallic Ti, acquired by depth profile sputtering of a thick Ti film deposited in the same chamber under the same conditions $\left(0.1 \AA / \mathrm{s}, 1 \mathrm{x} 10^{-6}\right.$ torr). This depth profiled $\mathrm{Ti}$ layer showed an oxygen incorporation of $\sim 25 \%$ in atomic concentration. A comparison of the $\mathrm{Au}, \mathrm{SiO}_{2}$ and $\mathrm{PtO}_{\mathrm{x}}$ spectra illustrates two main points: $i$ ) all spectra show a majority of titanium oxide species $\left(\mathrm{TiO}_{2}, \mathrm{TiO}_{\mathrm{x}}\right.$, and $\mathrm{TiO}$ ), a minor amount of $\mathrm{TiC}$ (as confirmed by the $\mathrm{C}$ (1s) spectra, not shown), and no metallic $\mathrm{Ti}$; and ii) the relative amount of $\left.\mathrm{TiO}_{2} \mathrm{vs}_{(\mathrm{TiO}}+\mathrm{TiO} / \mathrm{TiC}\right)$ varies with substrate, with the most $\mathrm{TiO} / \mathrm{TiC}$ found on the $\mathrm{Au}$ substrate. In contrast, the $\mathrm{PtO}_{\mathrm{x}}$ substrate shows exclusively $\mathrm{TiO}_{2}$, with almost no $\mathrm{TiO}$ and no TiO or TiC. The amount of $\mathrm{TiO}_{2}$ thus varies as $\mathrm{TiO}_{2-\mathrm{PtOx}}>\mathrm{TiO}_{2-\mathrm{SiO} 2}>\mathrm{TiO}_{2-\mathrm{Au}}$. The amount of TiO/TiC follows exactly the opposite trend, with $\mathrm{TiC}_{\mathrm{Au}}>\mathrm{TiC}_{\mathrm{SiO} 2}>\mathrm{TiC}_{\mathrm{PtOx}}$. These XPS data support the ATR-IR results that show this same same trend in $\mathrm{CH}_{2}$ absorption peak shift, peak width and absolute absorption intensity upon Ti deposition.

1 J.J. Blackstock, W.F. Stickle, C.L. Donley, D.R. Stewart, R.S.Williams, J. Phys. Chem. C, 2007, 111, 16.

${ }^{2}$ C.D. Wagner, A.V. Naumkin, A. Kraut-Vass, J.W. Allison, C.J. Powell, J.R. Rumble,Eds. NIST X-ray Photoelectron Spectroscopy Database 20, version 3.4 (Web version); National Institute of Standards and Technology: Gaithersburg, MD, 2003. 